\title{
Interdisciplinary Strategies in Management of Sub-Gingivally Fractured Teeth - A Sync at Various Levels
}

\section{Vishnusripriya J ${ }^{1 *}$, Anil Melath ${ }^{2}$, Subair $\mathrm{K}^{3}$ and Saicharan $\mathrm{G}^{4}$}

${ }^{1}$ Senior Lecturer, Department of Periodontics, Mahe Institiute of Dental Sciences and

Hospital, India

${ }^{2}$ HOD, Department of Periodontics, Mahe Institiute of Dental Sciences and Hospital, India

${ }^{3}$ Professor, Department of Periodontics, Mahe Institiute of Dental Sciences and

Hospital, India

${ }^{4}$ Senior Lecturer, Department of Conservative Dentistry and Endodontics, Mahe

Institiute of Dental Sciences and Hospital, India

*Corresponding Author: Vishnu Sri Priya J, Mahe Institute of Dental Sciences and

Hospital, Chalakkara, Palloor, Mahe, India.
Received: January 17, 2022

Published: February 15, 2022

(C) All rights are reserved by Vishnusripriya

J., et al.

\begin{abstract}
Sub gingivally fractured tooth requires a precisely planned interdisciplinary management strategies and complete understanding of the lesion. Complicated sub gingivally fractured teeth poses difficulties for the dentists to design efficient treatment plans as they demand interdisciplinary knowledge and approach. A comprehensive understanding of newer techniques, materials and their limitations is essential for achieving more functional and long-lasting anticipated results for the patient with such conditions. This review deals with various conventional treatment approaches and their contemporary modifications in treating a sub-gingivally fractured teeth.
\end{abstract}

Keywords: Sub Gingivally Fractured; Interdisciplinary; Contemporary; Treatment

\section{Introduction}

Regime for sub gingivally fractured tooth, is complex and an important criterion for success of a dentist. It requires a precisely planned interdisciplinary management strategies and complete understanding of the lesion. It all begins from a properly recorded case history including aetiology, history, clinical examination, pulpal status, radiographic examination, paving way for the diagnosis and relative treatment plan.

According to Olsburgh., et al. in 2002, The choice of treatment for a sub gingivally fractured tooth depends on the:

- Extent and Morphology of subgingival lesion,
- Length and morphology of the root,

- Zone of fracture line (cervical, middle and apical)

- $\quad$ Degree of fracture (partial and total);

- $\quad$ Count of fracture lines (simple, multiple and comminated);

- Situation of coronal fragment (displaced and nondisplaced).

- Presence or absence of a coronal segment

- Restorability of the traumatized tooth.

- Appearance in the aesthetically sensitive region.

Factors determining the prognosis of the condition includes secondary trauma, availability of the fractured fragment and better 
plaque control by the patient. Chances of healing with calcified tissue is poorest in cervical-third fractures.

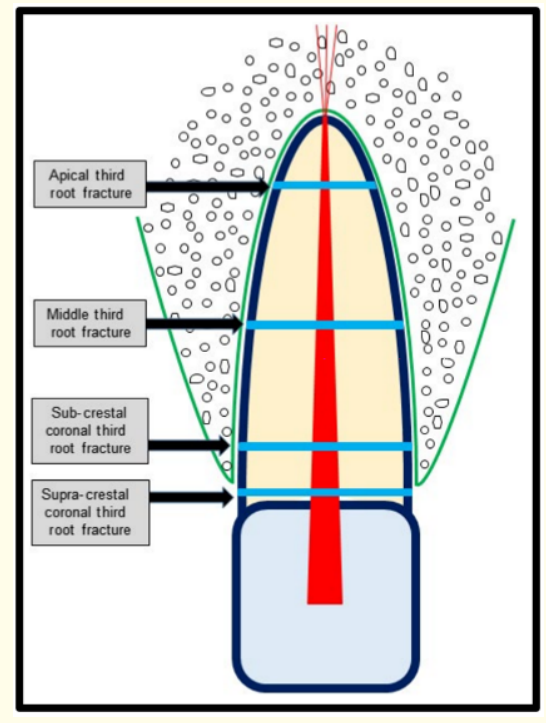

Figure A: Location of apical, middle, subcrestal and supracrestal root fractures (Abbott PV.et.al,2019) [1].

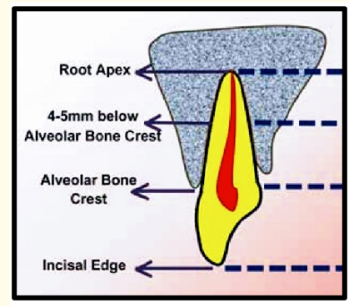

(b)

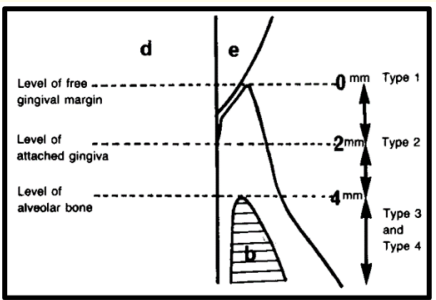

(c)
Figure B: Horizontal tooth fractures depending on the position of the fracture line (Neeraj Malhotra, 2011) [10].

Figure C: Classification of subgingival fractures by depth of fracture below the free gingival margin (Heithersay,1982).

\section{Conventional treatment strategies}

The interdisciplinary treatments require time, commitment and motivation both from the patient and the dentist. The literature reports several approaches for sub gingivally fractured teeth.
Reduction and stabilization

Subgingival fracture below alveolar bone crest with presence of coronal segment shows possible healing with conventional reduction and stabilization. Splinting in these cases should be maintained for 4 months. In patients with adequate oral-hygiene, permanent fixation and reattachment of the fractured fragment at the proximal contact areas to adjacent teeth with a resin-based or nano composite can be tried. Occlusal interferences on the injured teeth should be minimised.

\section{Reattachment}

Conditions where the coronal segment is available and fracture occurs at or coronal to the level of alveolar bone crest, reattachment of the fractured segments can be attempted with fibre-reinforced posts and dual cure resin-based composite material instead of fixed prostheses, implants or extraction.

\section{Post crowns}

The coronal segment is absent(lost), fracture line is above alveolar bone crest with apical sufficient root segment length. Exposure of crown margins by simple genioplasty or an apically repositioned flap surgery is performed.

\section{Other treatment alternatives}

Fracture line extending below the level of alveolar bone crest with sufficient apical root segment length, (or) fracture line is coronal and bacterial contamination is present through the gingival crest, the pulp tissue becomes necrotic, the following treatment alternatives are available:

- Crown-lengthening,

- Orthodontic extrusion,

- Intra-alveolar trans-positioning of fractured tooth.

Crown-lengthening (periodontal surgery)

Fracture line is not more than $1-2 \mathrm{~mm}$ below the alveolar bone crest with sufficient root length. Remove 1 - 2 mm of crestal bone along deepest part of the fracture and restore the normal $2 \mathrm{~mm}$ sulcus depth without violating biological-width. Periodontal osseous recontouring exposes the tooth margin with optimal root surface for an acceptable restorative finish-line. Later apical migration of gingival marginal tissue may compromise aesthetics. 


\section{Orthodontic extrusion}

Forced eruption, orthodontic eruption, vertical extrusion or assisted eruption is carried out in teeth with fracture line extending deeply in the interproximal or labial surface up to $6 \mathrm{~mm}$ below the alveolar crest and when crown lengthening would be un-aesthetic. The distance between fracture line and apex should more than 12 $\mathrm{mm}$ and a crown-root ratio of around 50:50 should be obtained.

Intra-alveolar trans-positioning of fractured tooth

It is done on an emergency basis, in severe luxation of fractured root. The tooth is precisely extruded by marginal luxation and stabilized at the appropriate position by interdental suturing and surgical dressing. In case fracture line is more apical on the labial side, a $180^{\circ}$ rotation is given before fixation and usually here the bone support around root is lost.

\section{Extraction}

Conditions with untreatable scenario, the fractured tooth is extracted without causing any damage to the alveolar processes, in the labio-lingual direction. Preservation of the apical fragment is recommended, as it contains vital pulpal tissue and retards alveolar process resorption. Later new layer of cementum and bone is deposited on roots along the fractured surface.

\section{Follow-up}

Clinical and radiographic re-evaluation is done at $4^{\text {th }}$ week, 6-8 ${ }^{\text {th }}$ week, 4-month, 6-month, 1-year and 5-year intervals. Patients is advised care for the injured teeth. Use of a soft brush and $0.1 \%$ chlorhexidine rinse prevents accumulation of plaque and debris.

\section{A synchronisation at various levels}

Interdisciplinary dentistry refers to dental treatment that uses more than one type of dental tactic. This type of multilevel care is taken for complex cases treated in multiple steps. The main benefits of this approach for clinician is advanced educational opportunities with improved coordination for patient management, through development of a streamlined treatment strategy. The patient is benefited with improved satisfaction as he gets the most appropriate treatment decision made by a team of experts.
Few recent innovative interdisciplinary strategies in treating a sub gingivally fractured teeth includes studies done by Parthiban., et al. in 2020 [12], treated sub gingivally fractured anterior tooth by an interdisciplinary approach using clear-aligner based orthodontic extrusion appliance. Singh., et al. in 2019 [17] treated a subgingival fractured tooth with active orthodontic treatment for 28 days, after sufficient extrusion, fibrotomy was done to evade relapse and stabilized for 8 - 12 weeks before the fabrication of a permanent post and core with adequate ferrule. Habbad., et al. in 2018 [7] successfully managed a sub gingivally fractured maxillary central incisor with biologic width invasion by surgical crown lengthening, endodontic treatment, cast post-core system and a crown. Gopal., et al. in 2017 [6] managed a sub gingivally fractured tooth using fiber-post and fragment reattachment. With 2years of follow-up for good esthetics as well as clinical and radiographic signs of periodontal health and root integrity, indicates success of an interdisciplinary treatment approach. Merve Mese., et al. in 2015 [11], treated a complicated subgingival fracture of an anterior tooth undergoing apexification. Multidisciplinary adhesive surgical approaches and fragment reattachment with an intracanal fiberpost provided successful clinically results while maintaining the structural integrity of the tooth.

\section{Future trends}

- $\quad$ Diode lasers are used to expose all the margins of the fracture and a study done by John R Christensen., et al. in 2018 [8] reported that use of lasers showed excellent haemorrhage control.

- $\quad$ Clear aligner -Parthiban., et al. in 2020 [12] used Clear aligner to fabricate the fractured segment template, and temporary tooth were placed to provide adequate esthetics.

- Flowable-Nano-Composite minimize the inclusion of air voids, reinforces the tooth by achieving higher bond strength with the fractured segments.

- $\quad$ Resin Based Sealers are used to treat teeth planned for restoration with light posts as eugenol-based sealers may inhibit the setting of resin cements.

- Minimally invasive microscopic approach. 

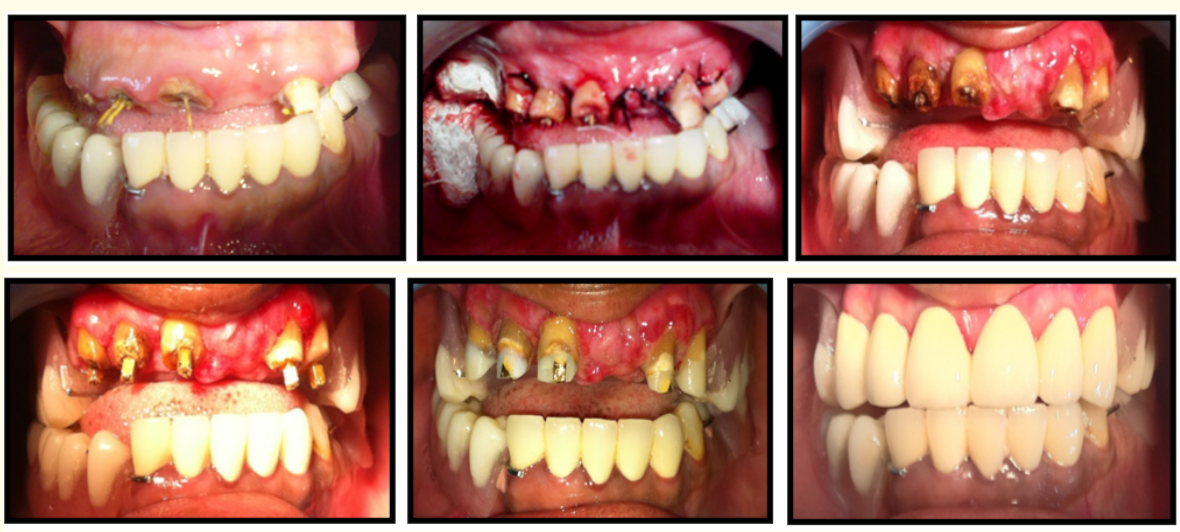

Figure D: A glimpse of similar Interdisciplinary approach attempted in our Institute.

\section{Conclusion}

As the trend is shifting toward implants, conservative management to preserve the natural tooth are overlooked. Complicated sub gingivally fractured teeth poses difficulties for the dentists to design efficient treatment plans as they demand interdisciplinary knowledge and approach. Contrary to belief, interdisciplinary dentistry is not confined to complex cases. A comprehensive understanding of newer techniques, materials and their limitations is essential for achieving more functional and long-lasting anticipated results for the patient. Therefore, it is necessary to have an interdisciplinary synchronisation at various levels to attain precise and custom-made treatment plans by sharing each other's expertise for the complete and predictable outcome.

\section{Bibliography}

1. Abbott PV. "Diagnosis and management of transverse root fractures". Dental Traumatology 35 (2019): 333-347.

2. Altun Ceyhan and Guven Gunseli. "Combined technique with glass-fibre-reinforced composite post and original fragment in restoration of traumatized anterior teeth - A case report". Dental Traumatology: Official Publication of International Association for Dental Traumatology 24 (2009): e76-80.

3. Dayanand Chole., et al. "Management of sub-gingival fractured teeth by multi-disciplinary approach: endodontics - forced orthodontic extrusion and prosthetic rehabilitation: a case report". International Journal of Contemporary Medical Research 3.4 (2016): 1198-1200.
4. Dede DO., et al. "Multidisciplinary approach to a subgingivally fractured incisor tooth: A case report". Journal of Dental Sciences 12.2 (2013): 190-194.

5. Devanna Raghu., et al. "Management of subgingivally fractured teeth: A multidisciplinary approach". Journal of Interdisciplinary Dentistry 1 (2011): 49.

6. Gopal R., et al. "Management of tooth fractures using fiber post and fragment reattachment: Report of two cases". Journal of Pharmacy and Bioallied Sciences 9 (2017): S295-298.

7. Habbad AS., et al. "Clinical Management of Maxillary Incisor with Complicated Crown-Root Fracture: A Case Report”. International Journal of Dentistry and Oral Science 5.1 (2018): 581-584.

8. John R C and Linwood ML. "Management of Subgingival Incisor Fractures with a Diode Laser". Interventions in Pediatric Dentistry Open Access Journal 2.1 (2018).

9. Karhade I and Gulve MN. "Management of Horizontal Root Fracture in the Middle Third via Intraradicular Splinting Using a Fiber Post". Case Reports in Dentistry (2016): 9684035.

10. Malhotra N., et al. "A review of root fractures: diagnosis, treatment and prognosis". Dent Update 38.9 (2011): 615-616.

11. Mese M., et al. "Multidisciplinary Management of Complicated Crown-Root Fracture of an Anterior Tooth Undergoing Apexification". Case Reports in Dentistry (2015): 521013.

12. Parthiban G., et al. "Multidisciplinary approach to the management of a subgingivally fractured anterior tooth using an 
aligner based esthetic orthodontic extrusion appliance - A case report". Saudi Endodontic Journal (2020).

13. Patil SS., et al. "Forced orthodontic extrusion for anterior traumatized teeth by a simplistic approach". The Journal of Dental and Allied Sciences 3 (2014): 111-113.

14. Raut AW., et al. "Management of complicated crown fracture by reattachment using fiber post: Minimal intervention approach". Journal of Natural Science, Biology and Medicine 9 (2018): 93-96.

15. Shanmugam J., et al. "Management of complicated Crown root fractured teeth by intra alveolar transplantation with $180^{\circ}$ rotation: Case series". SRM Journal of Research in Dental Sciences 5 (2014): 203-206.

16. Shetty AJ., et al. "Clinical management of a complicated crownroot fracture of maxillary central incisor in a 12-year-old patient". International Journal of Pedodontic Rehabilitation 3 (2018): 76-79.

17. Singh N., et al. "Management of subgingival fractured tooth". Journal of the International Clinical Dental Research Organisation 11 (2019): 101-510.

18. Sirisha K., et al. "Management of crown root fractures: A novel technique with multidisciplinary approach". Journal of Dr. NTR University of Health Sciences 2 (2013): 72-77.

19. Suresh KS., et al. "Management of lateral incisor fractured at crestal level: An interdisciplinary case report". Indian Journal of Dental Sciences 10 (2018): 237-240.

20. Verma KG., et al. "Orthodontic extrusion of subgingivally fractured tooth using a removable appliance: An alternative treatment to reestablish biological width". Indian Journal of Dental Research 25 (2014): 678-680.

\section{Assets from publication with us}

- Prompt Acknowledgement after receiving the article

- Thorough Double blinded peer review

- Rapid Publication

- Issue of Publication Certificate

- High visibility of your Published work

Website: www.actascientific.com/

Submit Article: www.actascientific.com/submission.php

Email us: editor@actascientific.com

Contact us: +919182824667

Citation: Vishnusripriya J., et al. "Interdisciplinary Strategies in Management of Sub-Gingivally Fractured Teeth - A Sync at Various Levels". Acta Scientific Dental Sciences 6.2 (2022): 36-40. 